\title{
Research on a Novel Heat Recovery Method for Flue Gas
}

\author{
Qing $\mathrm{HAO}^{1, a}$, Yue $\mathrm{YANG}^{2, \mathrm{~b}}$ \\ ${ }^{1}$ Bohai Oil Water and Power Service Company, Donggu Oil New Village, Binhai New Area, Tianjin \\ 300452, China \\ ${ }^{2}$ School of Energy and Environmental Engineering, Hebei University of Technology, Tianjin 300401, \\ China.
}

${ }^{a}$ Corresponding author email: haoqcnooc@sina.com, bemail: 1324170284@qq.com

\section{Keywords: Flue Gas; Energy; Waste Heat; Recovery}

\begin{abstract}
The energy consumption is increasing year after year with the development of economy in our country. Improving and optimizing the way of energy use constantly is necessary. Industrial waste heat is the energy which is not used in the thermal conversion equipment and energy-using equipment in the process of production. In the research, a novel system is developed for waste heat recovery. Parts of sensible heat and latent heat of the low temperature flue gas are recycled through the recuperative heat exchanger which reduces the temperature of the exhausted flue gas. Comparing with the common boiler and the depth recovery system of flue gas waste heat under different conditions, it was found that the latter not only increases the available heat and thermal efficiency, but also reduces the exhausting temperature of flue gas.
\end{abstract}

\section{Introduction}

Flue gas generated from boiler is a material with thermal energy. Energy is an essential part of the development. It promotes the development of the society by combining with other means of economic growth. Ensuring stable energy is the key of the national development strategy [1]. At the same time, the impact of energy production and consumption to the environment also increases significantly. Now all countries in the world are facing the problem of coordination the economic development and environmental protection [2, 3]. The industrial waste heat resources include metallurgical, chemical, building materials, glass, paper production, textile and mechanical. The waste heat resource is very rich and the recycling potential is enormous in our country. If it is not recovered, a lot of waste heat will be discharged in various forms which lead to low energy efficiency and serious environmental pollution in our country [4-6]. The waste heat mainly comes from high temperature flue gas which is count for $50 \%$. The rest come from cooling substance, waste water and gas, chemical reaction and so on[7].

In the period of the 11th five-year plan of China, about 88.16 million tons of standard coal were developed and installed 12 million KW. The industrial waste heat resource utilization rate was 34\%. However, by the end of 2013, the standard coal had been developed about 130 million tons and installed 26 million $\mathrm{KW}$ and the industrial waste heat resource utilization rate reached $38 \%$. By the end of 2020, the expecting utilization rate of the industrial waste heat resource could reach $55 \%$ which can increase about 50 million tons of standard coal and install 9 million KW in the period of the 13th five-year plan [8, 9].

While there are still some problems to be solved in the industrial waste heat recovery, such as the waste heat utilization rate is very low and the comprehensive utilization is poor. Meanwhile most of the waste heat uses only once which does not recycle the different grade waste heat from senior to junior and most of low temperature waste heat is not being used. Heat exchange equipment for waste heat recovery plays an important role and it is often used as the target of major technology development $[10,11]$. In the future energy saving effects, more than $70 \%$ will depend on the direct energy saving. At the same time the proportion of recycling waste heat in energy saving will increase year by year [12].

Because the natural gas contains much hydrogen which will generate much water vapor after 
combustion, the temperature of the flue gas which is exhausted by natural gas burner is very high [13]. In order to recover sensible heat of the flue gas and latent heat of water vapor, enterprises usually install flue economizer and air heater and spray device to recycle heat. For the specific heat of air is very low, it is difficult to recover the latent heat of the water vapor in the flue gas by air heater. Usually it will be exhausted when the temperature of flue gas down to about $50{ }^{\circ} \mathrm{C}$. Parts of the sensible heat and latent heat of the flue gas could be recycled in this way [14]. While there is still half of the latent heat cannot be recycled. For spray device of heat recovery, the patent CN201120133195.9 shows a central heating system using absorption heat pump to recycle waste heat, which recycle waste heat by direct contact with flue gas and water. Because this system adopts the absorption heat pump units and covers large area, the constructing cost is very high [15].

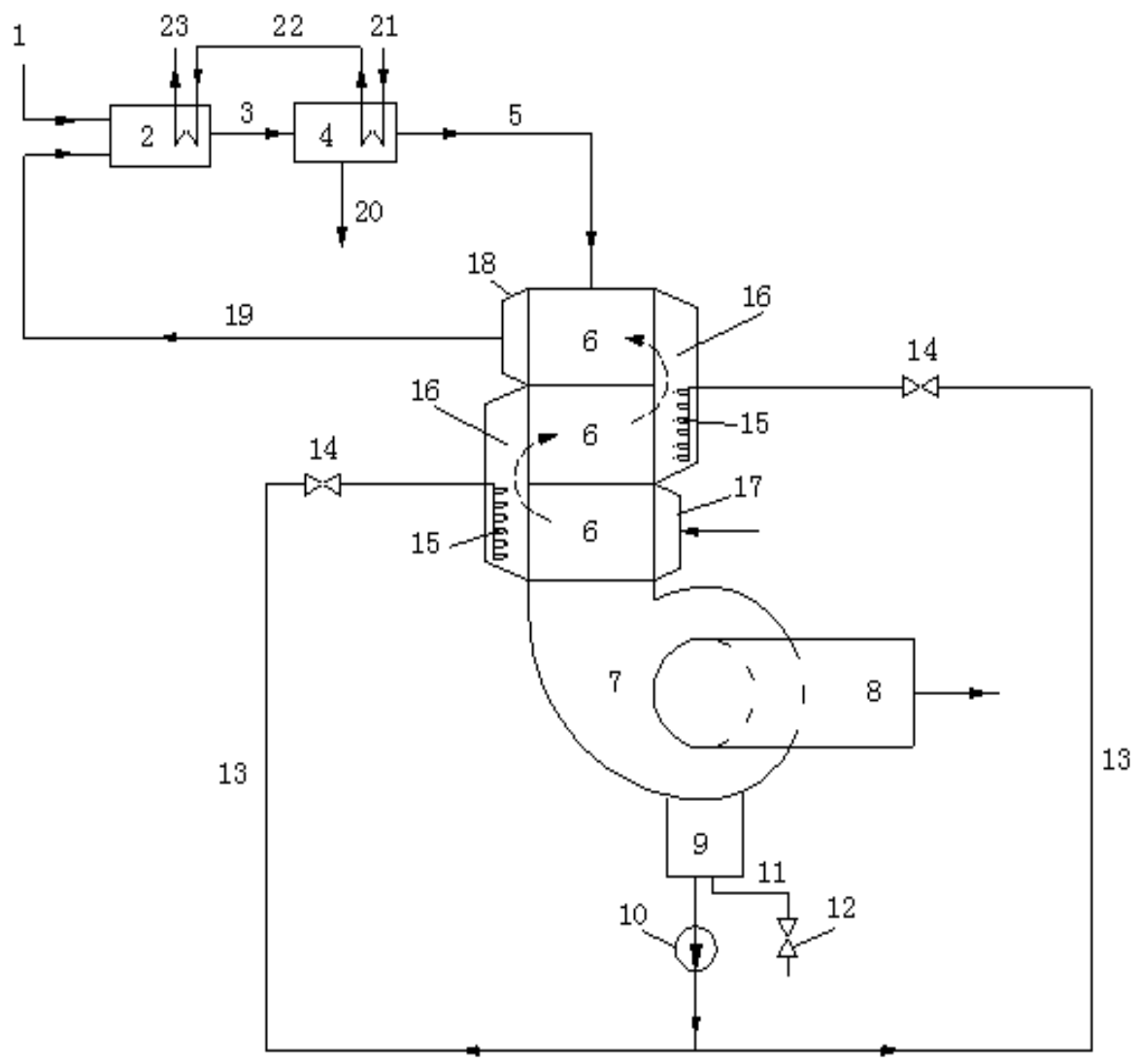

Fig.1. The waste heat recovery system of low temperature flue gas

\section{Technical Solution Scheme}

The novel waste heat recovery system is shown in Fig. 1 . The gas inlet tube 1 connects with gas combustion equipment 2 . The high temperature flue gas pass 3 connects the high temperature flue economizer 4 with gas combustion equipment 2. The low temperature flue pass 5 connects the recuperative heat exchanger 6 with the high temperature flue economizer 4 . The three recuperative heat exchangers 6 connected in sequence of the flue gas flowing direction, and the gas condensate centrifugal separator 7 are tangential connection. Flue gas pass outlet 8 links to the center of the flue gas condensate centrifugal separator 7 . The bottom of flue gas condensate centrifugal separator 7 links to the collecting well 9. The bottom of collecting well pipe connects the condensate pipe 13 with drain pipe 11 . The water mist controlling valve 14 and the water mist nozzle 15 are installed on the condensate pipe 13. There is a condensate extraction pump 10 to increase the pressure of the water. The air from the inlet 17 enters into the recuperative heat exchanger 6 and becomes hot air, then flows into the air tube 19 through the air outlet 18 and goes into the gas combustion equipment 2. The heated material (usually water) enters into the economizer 4 through the heated substance inlet pipe 21 and exchanges heat with the hot flue gas, then goes into the gas combustion equipment 
2 and discharges from outlet pipe 23. Part of vapor is condensed into water in the high temperature flue economizer 4 and then drains water from economizer condensate pipe 20.

\section{Simulation Study}

The depth recovery system of waste heat on low temperature flue gas is simplified and shown in Fig. 2.

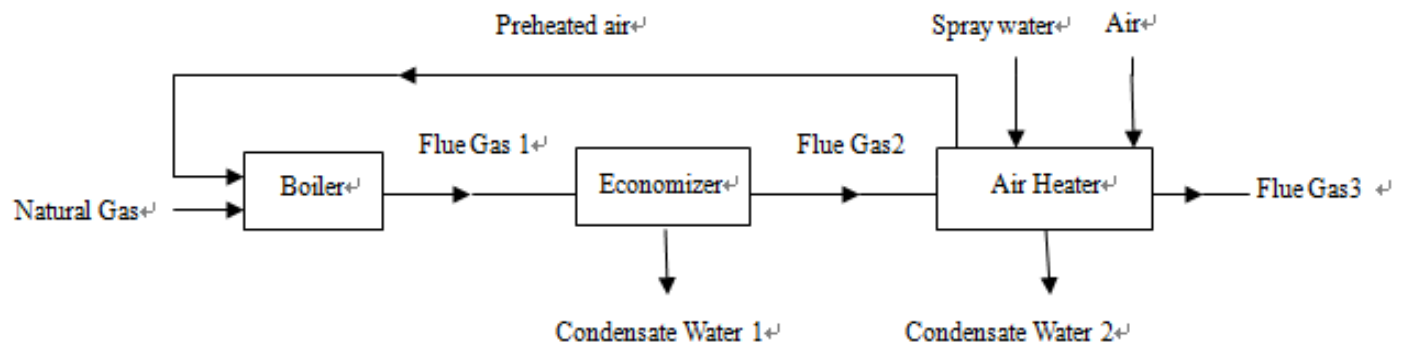

Fig. 2 The simplified waste heat recovery system of low temperature flue gas

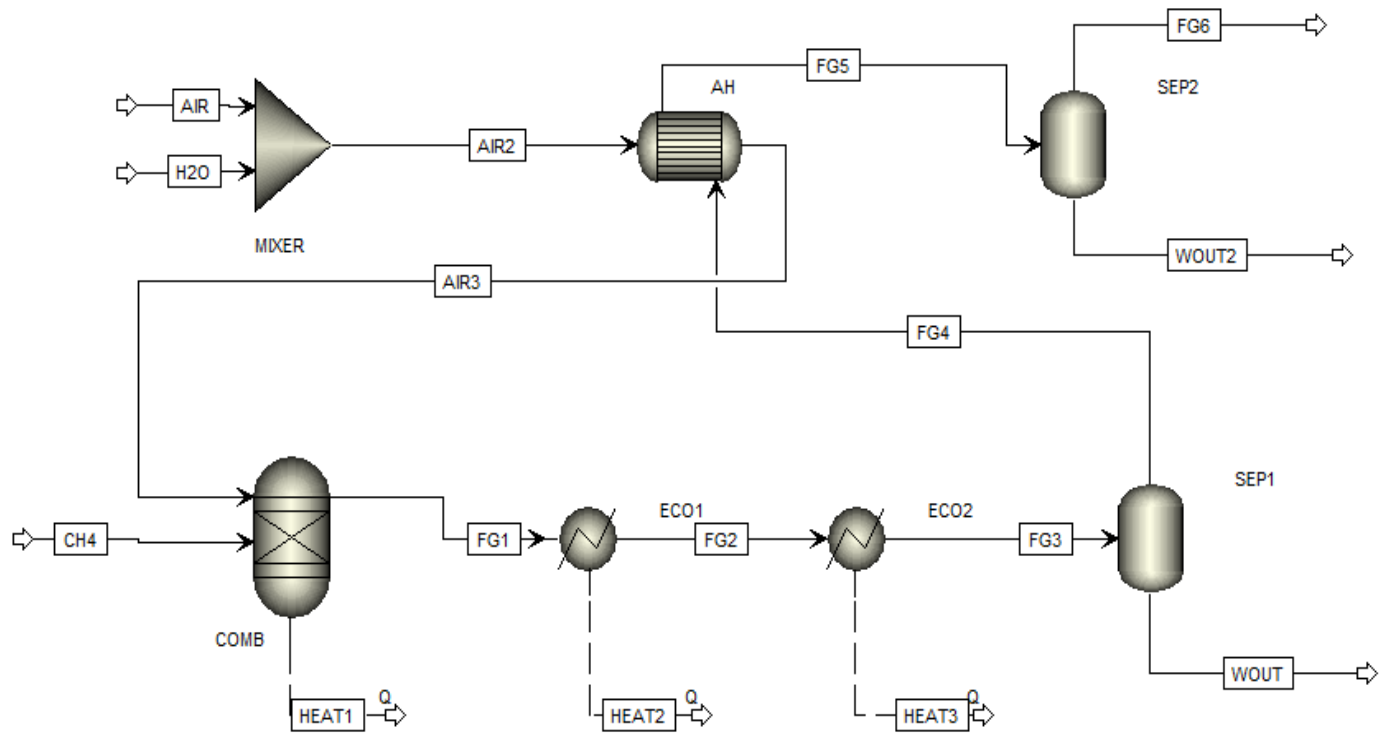

Fig. 3. The simulation system of waste heat recycling

The study is based on common gas boiler combustion system whose rate of gas flow is 735 $\mathrm{Nm}^{3} / \mathrm{h}$ and environmental temperature is $-10^{\circ} \mathrm{C}$. The excess air coefficient is 1.15 and exhaust flue temperature is $130^{\circ} \mathrm{C}$. After adding the economizer and air heater for depth recovery of waste heat, the temperature of flue gas 2 is 50 . The temperature of flue gas 3 is $30^{\circ} \mathrm{Cand}$ the temperature of water on air heater air side is $50{ }^{\circ} \mathrm{C}$. The operation conditions under the three different environmental temperatures $\left(-20^{\circ} \mathrm{C}, 10^{\circ} \mathrm{C}, 5^{\circ} \mathrm{C}\right)$ were analyzed according to the above settings.

The simulation system used for depth recovery of flue gas waste heat is shown in Fig. 3. In this system, the combustion of is a reactor which is based on the principle of Gibbs free energy minimization. The module can deal with the three-phase equilibrium and ensure the Gibbs free energy minimization during the reaction. In the 1870s the American chemist Gibbs developed some classical theories like Gibbs free energy, chemical potential and the phase rule, which laid the foundation of chemical thermodynamics. Gibbs free energy is also called the Gibbs function. Therefore, the Gibbs free energy $G$ of mixture in the Gibbs reactor can be described as a mathematical formula as follows:

$$
\tilde{G}=\sum_{i=1}^{N} n_{i} G_{i}
$$

In which, $n_{i}$ is the number of moles of the components and $\mathrm{N}$ is the total number of components. $G_{i}$ represents the chemical potential of components. And according to the definition of chemical potential in chemical thermodynamics, $G_{i}$ describes as follows: 


$$
\begin{aligned}
G_{i} & =G_{i}^{0}+R T \ln \frac{f_{i}}{f_{i}^{0}} \\
f_{i} & =\frac{n_{i}}{\sum_{i=1}^{N} n_{i}} \varphi_{i} P
\end{aligned}
$$

In which, $G_{i}^{0}$ is the chemical potential of components under the standard state and $f_{i}$ is the fugacity of components in the mixture (is a function based on the number of moles and temperature). $\mathrm{P}$ refers to the pressure and $f_{i}^{0}$ is the fugacity of component under the standard state. $\mathrm{R}$ is the gas constant and $\mathrm{T}$ is the absolute temperature.

The rule of the Gibbs reactor getting equilibrium is the Gibbs free energy minimization, that is:

$$
\min \sum_{i=1}^{N} n_{i} G_{i}
$$

The quality should keep conservation during the Gibbs react and the key is the total number of atoms unchanged. If make $B_{j}$ represents the number of atoms before reaction and $B_{i j}$ is the number of $\mathrm{j}$ in the components, then the mass balance can be expressed as mathematical expressions below:

$$
\sum_{i=1}^{N} n_{i} \beta_{i j}=B_{j}
$$

At the same time, the energy should also reach equilibrium during the reaction:

$$
\sum_{i=1}^{N} n_{i} H_{i}=Q
$$

In the formula, $\mathrm{Q}$ is the energy before the reaction and $H_{i}$ is the energy of component after the reaction [16].

In the simulation system, the mixture of water and air should pre-heating the air heater first. The temperature of injected water is $50^{\circ} \mathrm{C}$ and the air temperature changes with the surroundings. In the simulation, it is assumed that the temperature of air is $5^{\circ} \mathrm{C},-10^{\circ} \mathrm{C},-20^{\circ} \mathrm{C}$ respectively. The flue gas temperature reduces to $130^{\circ} \mathrm{C}$ after passing the first level economizer and then the temperature of flue gas goes down to $50^{\circ} \mathrm{C}$ after passing the second level economizer. After the flue gas separates water and part of water is pumped and used for atomization. The water mist enters into the air side of air heater. The flue gas temperature reduces to $30^{\circ} \mathrm{C}$ by exchanging heat. In this process the amount of spray water is adjusted to achieve the maximum recovery of flue gas waste heat under the different temperatures. The simulation calculation of whole system including boiler, economizer and heat exchanger is completed though the software after the specification is made.

\section{Results and Discussion}

The simulation is performed on the basis of the common gas boiler combustion system. The gas heating value is $37.15 \mathrm{MJ} / \mathrm{Nm}^{3}$ and the boiler heat load is $7 \mathrm{MW}$ with the thermal efficiency of $92.3 \%$ and the volume ratio of water vapor of $16.2 \%$ in the flue gas. After adding the economizer and water mist spraying air heater, the simulation calculation results are as follows:

Adding a flue gas heat exchanger in the exhausting flue system of conventional combustion boiler could reduce the temperature of exhausting flue from $130^{\circ} \mathrm{C}$ to $50^{\circ} \mathrm{C}$ and the available heat load increases by $0.49 \mathrm{MW}$. At the same time it could get the $50^{\circ} \mathrm{C}$ condensated water of $324 \mathrm{~kg}$ each hour and the volume ratio of water vapor in the flue gas becomes $12.3 \%$. In the depth recycling system of flue gas waste heat, the flue gas at $50^{\circ} \mathrm{C}$ exchanges heat with the air which is injected $50^{\circ} \mathrm{C}$ water mist. It will be discharged when the temperature of flue gas reduces to $30^{\circ} \mathrm{C}$. It was found in the simulation that there is a rational range of the amount of injected water. The minimum amount of injected water needs to satisfy that the evaporation can absorb the latent heat and sensible heat to recover them of flue gas. After exchanging heat, the temperature of air with injected water is lower than the flue gas inlet temperature and a large amount of water sprayed into the air becomes vapor after the heat exchanger. It can recover the waste heat and meet the designed exhausting temperature of flue gas if the amount of water is between the maximum and minimum. Within the scope, the more water spray, the larger amount of steam will produce in the furnace exit and more water will condensate in the economizer. The parameters under different environmental temperatures $\left(T_{0}\right)$ have been summarized in Table 3 . 
Table 3 Parameters in the system of depth recovery of waste heat

\begin{tabular}{|c|c|c|c|c|c|c|}
\hline \multirow{2}{*}{$\mathrm{T}_{0} /{ }^{\circ} \mathrm{C}$} & $\begin{array}{c}\text { Spray } \\
\text { water/(kg/h) }\end{array}$ & $\begin{array}{c}\text { Temperature } \\
\text { of air } /{ }^{\circ} \mathrm{C}\end{array}$ & $\begin{array}{c}\text { Proportion of } \\
\text { vapor in the } \\
\text { exit of boiler }\end{array}$ & $\begin{array}{c}\text { Condensate } \\
\text { water of } \\
50^{\circ} \mathrm{C} / \mathrm{kg}\end{array}$ & $\begin{array}{c}\text { Condensate } \\
\text { water of } \\
30^{\circ} \mathrm{C} / \mathrm{kg}\end{array}$ & $\begin{array}{c}\text { Available } \\
\text { heat } \\
\text { load/MW }\end{array}$ \\
\hline \multirow{2}{*}{5} & 500 & 48.9 & 0.216 & 824 & 590 & \multirow{2}{*}{8.01} \\
\cline { 2 - 6 } & 542 & 40.3 & 0.220 & 866 & 590 & \\
\hline \multirow{2}{*}{-10} & 432 & 48.8 & 0.209 & 756 & 590 & \multirow{2}{*}{7.96} \\
\cline { 2 - 6 }-20 & 484 & 38.3 & 0.214 & 808 & 590 & \\
\cline { 2 - 6 } & 389 & 48.3 & 0.205 & 713 & 590 & \\
\hline
\end{tabular}

It is found from the simulation that the available heat load which produces in the ordinary boiler is different from the depth recovery system of waste heat. The three cases below show the conditions of available heat load under the different exhausting temperatures and different environmental temperatures.

Case 1: when the surrounding temperature is $5^{\circ} \mathrm{C}$ and exhausting temperature is $130^{\circ} \mathrm{C}$, the available heat load of general boiler is $7.06 \mathrm{MW}$ while the depth recovery system of waste heat is 8.01MW with the increase of $13.5 \%$.

Case 2: when the surrounding temperature is $-10^{\circ} \mathrm{C}$ and exhausting temperature is $130^{\circ} \mathrm{C}$, the available heat load of general boiler is $7 \mathrm{MW}$ while the depth recovery system of waste heat is 7.96MW with the increase of $13.7 \%$.

Case 3: When the surrounding temperature is $-20^{\circ} \mathrm{C}$ and exhausting temperature is $130^{\circ} \mathrm{C}$, the available heat load of general boiler is $6.98 \mathrm{MW}$ while the depth recovery system of waste heat is 7.94MW with the increase of $13.8 \%$.

With taking the example of case 2, the calculation is according with the low calorific value of fuel. It was concluded that the thermal efficiency of boiler is $105.0 \%$ after using the depth recovery system of waste heat, with the increase of $12.7 \%$ comparing to the thermal efficiency of general boiler of $92.3 \%$.

\section{Conclusion}

To increase the thermal energy utilization of the material flue gas from boiler, a depth recovery system of waste heat was proposed, and the system process and control method were introduced in details. The components and parameters of the system were designed and simulation was performed. It was found that the waste heat recovery system can not only increase the available heat load, but also improve the thermal efficiency comparing to the common boiler in energy saving. So the study of this system has a great significance on energy conservation and energy reasonable use.

\section{References}

[1] Hong. Li, Liang. Dong, Hongxia. Duan. The comprehensive evaluation and structure optimization research of China renewable energy development [J]. Resource Science. 2011 (03) 431-440

[2] Tao. Xiao. The study on the relationship between energy consumption and economic growth in China [D]. ChongQing University. 2013

[3] H.Y. Shang, P. Jiang: The structure decomposition of the factors of energy consumption in China [J] , 2009(02)

[4] L.B. Liu, L. Fu, SH.G. Zhang: The design and analysis of two exhaust heat recovery systems for public shower facilities[J], 2014 (132) 267-270

[5] H.K. Li, Y. Li, CH.W. Gu: An overview of domestic technologies for waste heat utilization[J], Vol. 2011 (29) 123-125 
[6] Jun. Li. Equipment Selection and Economic Analysis of Waste Heat Utilization System in Utility Boiler [J]. 2014

[7] Yun. Zhou, Kang. Wang, Siming. Chen. Industrial waste heat and waste heat utilization and expectation [J] . Sci-Tech Information Development and Economy. 2010 (23) 162-164

[8] Dianting. Wu, Xiaoyan. Yue. The urgency and difficulty of implementation of the 11th five-year planning target [J]. Recycle Economy.2007 (06) 15-18

[9] Yousheng. Zhang. Energy planning: retrospect of 11th five-year planning and looking forward to 12th five-year planning [J].Recycle Economy. 2010 (12) 9-12

[10] Jia. Meng. The optimization research for recovery and utilization program of waste heat in industrial flue gas [D]. Huazhong University of Science and Technology. 2008

[11] Hongkui. Lian, Yan. Li. The reviewed of industrial waste heat recycling technology in china [J] . Super Hybrid Engine. 2011 (02) 123-128+133

[12] Cuixia. Gao, Mei. Sun. Optimization of Chinese energy structure based on portfolio theory [J] . Energy, 2014 Elsevier

[13] Xiaohui. Zhang, Dawei. Liu. The technology of flue gas waste heat recovery on gas-fired boilers [J]. Industrial Boiler. 2008 (04) 4-8

[14] Shuai. Zhou. Heat condensate recovery research and application of gas-fired boiler flue gas [D]. Shandong University. 2012

[15] Bo. Qin, Chao. Wu, Guangming. Sui. The depth of reclaiming the residual heat of the flue gas of gas-fired boiler [J]. Harbin University of Science and Technology. 2014 (05) 71-75

[16] Juncai. Zhang. The calculation and application of gibbs free energy [J].XianYang Normal Junior College Journal. 1999 (03) 49-53 